\title{
$\widehat{A}$ Madridge \\ madridge Journal of Dentistry and Oral Surgery \\ Interconnecting Scientific World
}

Review Article

Open Access

\section{Clinical Appearances of Dental Implant Overload and Precautions}

İrem Çötert, and Hamit Serdar Çötert*

Department of Prosthodontics, Faculty of Dentistry, Ege University, Izmir, Turkey

\section{Article Info}

*Corresponding author:

Hamit Serdar Çötert

Department of Prosthodontics

Faculty of Dentistry

Ege University

Turkey

Tel: +902323880327

Fax: +902323880325

E-mail: serdar@cotert.com

Received: July 19, 2017

Accepted: July 21, 2017

Published: July 28, 2017

Citation: Çötert I, Çötert HS. Clinical Appearances of Dental Implant Overload and Precautions. Madridge J Dent Oral Surg. 2017; 2(2): 71-76.

doi: $10.18689 / \mathrm{mjdl}-1000117$

Copyright: $₫ 2017$ The Author(s). This work is licensed under a Creative Commons Attribution 4.0 International License, which permits unrestricted use, distribution, and reproduction in any medium, provided the original work is properly cited.

Published by Madridge Publishers

\begin{abstract}
\section{Objectives}

Despite vertiginous success and impressive satisfaction from dental implants, the issue of implant failure still creates a major concern for dental operators.

\section{Clinical Considerations}

Clinical exhibitions of implant overload are varying from the abrasion, deformation, crack or fracture of various parts of the superstructure prosthesis and/or various parts of the fixture, abutment and main screw, to the inflammatory response and/or infectious changes of periimplant soft tissues including host bone. Disintegration of the implant from the surrounding bone and the ending of the implant-supported prosthesis' service should also be considered in implant overload.
\end{abstract}

\section{Conclusions}

Various clinical exhibitions of dental implant overload have been discussed in present paper.

\section{Clinical Significance}

Kinds, etiologic factors and precautions of the failures affecting implants, incorporated prostheses and connecting elements are important in order to establish the long-term reliable service for implant-consisting prosthodontic treatments.

Keywords: Dental Implant; Implant Failure; Implant Overload; Periimplantitis.

\section{Introduction}

Dental implants widened the range of prosthodontic treatments in order to the replacement of missing teeth [1]. Recently, most of the edentulous cases can be treated with implant-supported prostheses. Unsuitable bone and/or soft tissue conditions can be improved surgically $[2,3]$. General and specific contraindications limiting the implant application have been discussed in related literature $[1,4,5]$. Despite acceptable service duration and high survival statistics, the issue of implant failure still creates a major concern for dental operators as a fact [1,5-11]. Osseointegration was reported as a good indication of clinical success of dental implants referring to the direct anchorage to the surrounding bone [11-13].

Various surgical complications such as the hemorrhage, hematoma, neurosensory disturbances, and fracture of mandible, inflammation and/infection, failure of host bone and/or surrounding soft tissue preservation; which are inhibiting the establishment of a reliable osseointegration were met in reviewed literature [6-8]. Such circumstances were generally accepted as the main clinical exhibition of the implant failure $[1,5,7,8,11,14]$. However, loss of dental implants in early period is only one of the well-known complications 
related with dental implant supported fixed or removable prostheses and underlying implants. Except surgical complications, implant-supported prostheses may also fail in late period [15-25]. Occlusal forces exceeding the biologically acceptable limit may cause harmful effects on the various components of the implant-supported prostheses. Clinical appearances of the implant overload create a wide spread spectrum consisting several kinds of failures. The aims of this study are to overview and discuss the implant failures attributed to overload with the help of sample cases.

\section{Overview}

Dental implant failures may appear either in early (preprosthetic) or late (post-prosthetic) period [8]. Complications that arise in pre-prosthetic period, mostly related with surgical intervention [11]. Neurosensory disturbance, hematoma, hemorrhage, loss of tooth vitality, lack of primary stability, implant loss and mandibular fracture are some of the well known surgical complications [8]. Inappropriate preoperative planning, traumatic surgery and infections of the host bone and peri-implant soft tissues may lead such failures [5,7,11].

Basic complications of late (post-prosthetic) period have been divided into three main categories as infection, overload and other causes $[1,6]$. Overload and infection or the combination of both, were reported as the most important factors associated with late failures [11]. Very wide range of the clinical manifestations indicating occlusal overload can be seen in daily clinical practice. These exhibitions are varying from the abrasion, deformation, crack or fracture of various parts of the superstructure prosthesis and/or various parts of the fixture, abutment and main screw, to the inflammatory response and/or infectious changes of periimplant soft tissues including host bone. Disintegration of the implant from the surrounding bone and the ending of the implant-supported prosthesis' service should also be mentioned among the clinical manifestations of overload $[6-8,25]$.

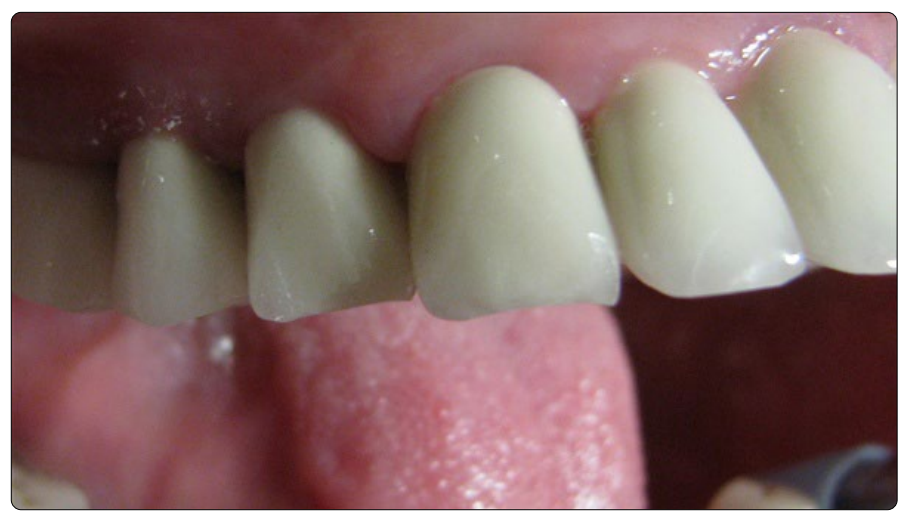

Figure 1. Veneer ceramic of an implant supported bilayer zirconia single crown replacing tooth no14 fractured due to the premature contact occurred in lateral movement.

\section{Structural Failures}

Neither fixed, nor removable prostheses are exempted from the structural failures such as the wear, crack or fracture of the esthetic veneers, artificial teeth or denture base. Meanwhile, components of precision attachments of the removable prostheses may also deformed, fractured or loosen under occlusal loads $[6,7,20,22]$. Fractured veneer ceramic of an implant supported bilayer zirconia single crown was represented in figure 1 . Fracture characteristic indicated the possible occlusal interference during the lateral excursive movement. In a comparative study, significantly more veneer fractures were found in FPDs (fixed partial dentures) on implants in comparison with FPDs on natural teeth and these kind of technical failures were observed as associated with bruxism and terminal extensions [10]. Veneer fracture rate of implant supported FPDs was reported as $22 \%$ and this ratio was found greater than the similar complications of single crowns, FPDs, all-ceramic crowns, resin-bonded prostheses and post-cores [7]. Except premature contacts during the centric and eccentric relations, nonpassive fit of FPD frameworks was also found susceptible to lead implant overload and veneer fractures [20].

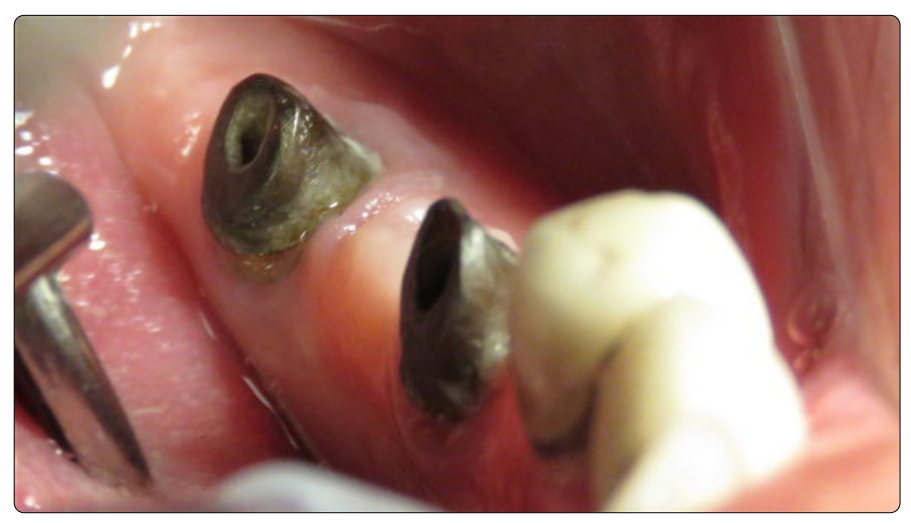

Figure 2. Abutments of an FPD debonded due to the improper axial convergence.

Dislodgement of the FPD is a specific complication for the cement-type implant super structures [6]. Rate of FPD loss over 4-5 years was found similar with implant supported, tooth supported and mixed reconstructions [10]. However, splinting to natural dentition, even with a stress-breaking attachment, has been reported as one of the major causes of implant overload [25]. Excessive reduction or improper angulation of axial convergence of the abutments may weaken the retention and resistance of FPD by creating tipping path. Figure 2 represents the abutments of a debonded FPD due to the improper axial convergence.

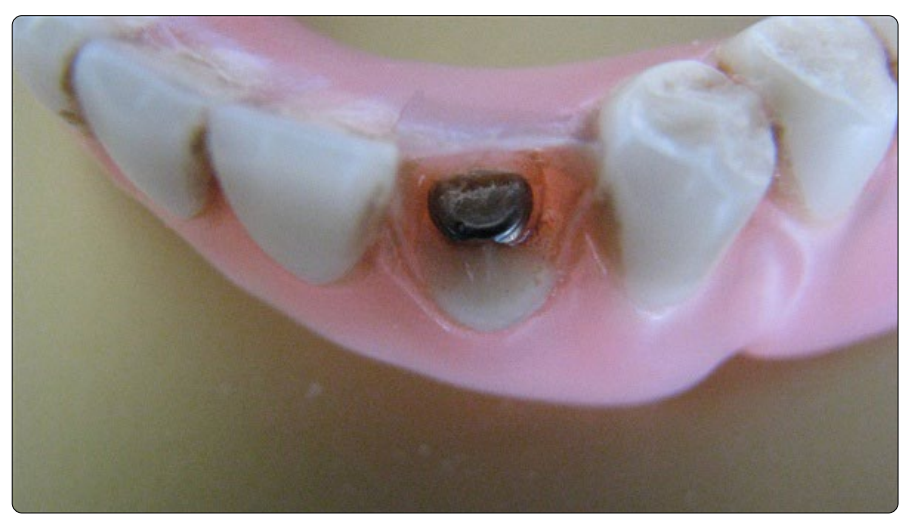

Figure 3. Artificial tooth of an implant-retaining overdenture fractured due to the rigid relation between the components of precision attachment. 


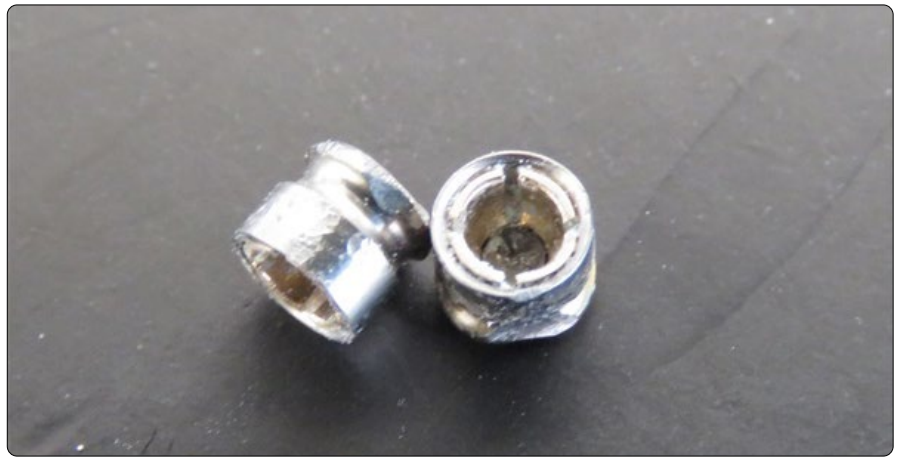

Figure 4. Precision attachment females an implant-retaining overdenture failed due to the harmful effects of non-parallel path of insertion.

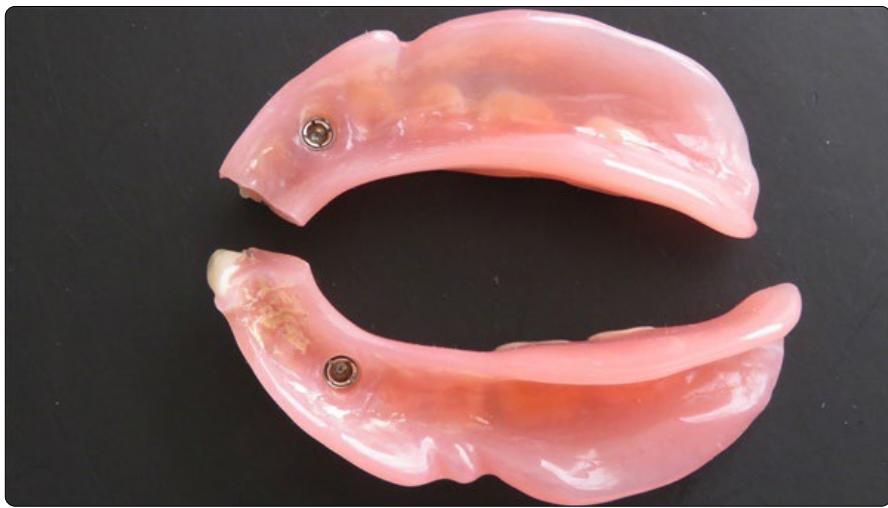

Figure 5. Fractured mandibular overdenture due to the absence of metal framework.

Figure 3 shows the fracture of the artificial tooth covering the precision attachment of an implant-retaining overdenture. Precision attachment females are ordinarily tend to wear, deform and loosen regardless of the material and need to be replaced [26]. However, predisposing factors like premature occlusal contacts both in centric and eccentric relations, nonparallel path of insertion and the insufficient vertical spacing for attachment mechanism may shorten the service duration of the precision attachments retaining the overdentures to the underlying implants $[8,24,26]$. Loosening of the overdenture retentive mechanism was reported as the most common implant complication with 33\% while the fracture of overdenture attachment female was 16\% [7]. Type of the retentive elements supporting overdentures was mentioned as one of the 10 risk factors for implant overload [9]. Figure 4 shows the precision attachment females failed under such conditions. Figure 5 represents a broken mandibular overdenture retaining by two sets of implants and precision stud attachments. Ratio of the implant-retaining overdentures needing to be relined was reported as 19\% [7]. Negligence of such routine requirement may lead overdenture fractures. In addition, the absence of a metal framework was also supposed to cause overdenture fracture [9].

Loosening of the main screw may frequently appear in implant supported superstructure prostheses either fixed or removable $[6,8,22,23]$. Main screws have to keep the parts of the implants together while confronting functional and parafunctional forces [22]. With this consideration, repetitive loads influencing the body-abutment joint in non-axial directions, may lead micro-movements and consequent loosening and/or fracture of the screw [23]. Non-passive fit of fixed prostheses, employment of the angulated abutments, and the presence of terminal extensions may serve to create overload and loose or fracture the screws [9]. Lack of posterior support was reported to have negative influence on the implants in anterior region. It has been concluded that this effect might result adverse occlusal forces on anterior implants, may cause fremitus, splaying of anterior teeth, accelerated wear and screw loosening [22]. Screw loosening was reported as the first detectable sign of implant overload, and warrant immediate action [25].

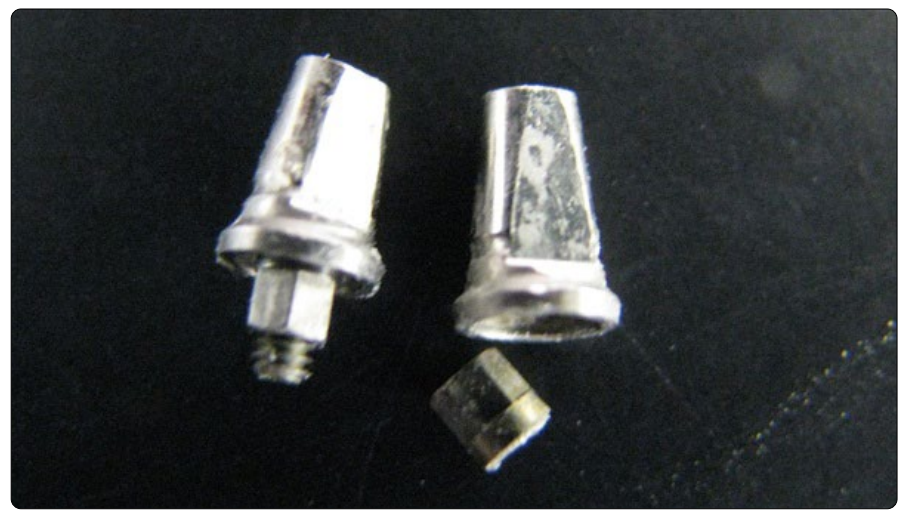

Figure 6. An abutment fractured under overload and/or excessive tightening with its intact original.

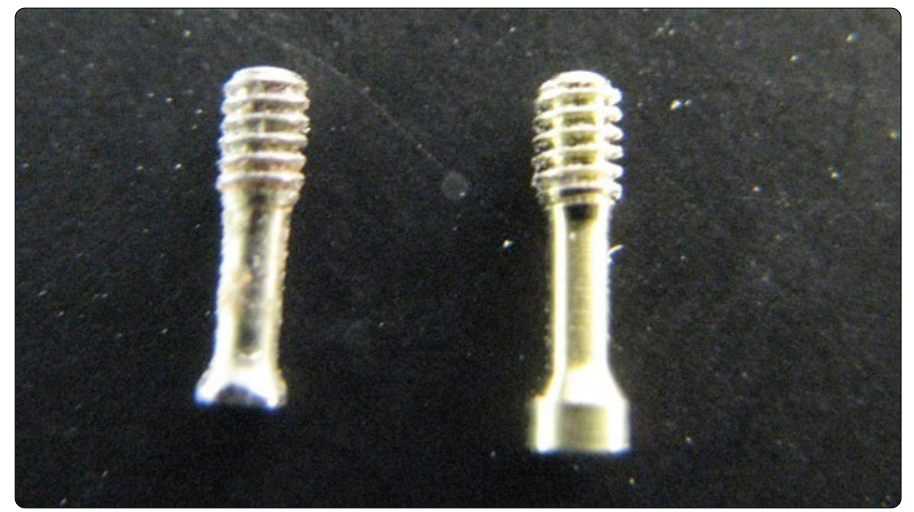

Figure 7. A main screw fractured under overload and/or excessive tightening with its intact original.

Various parts of implants like screws, abutments and fixtures may be deformed and/or fractured under occlusal loads exceeding materials' strength [20]. A fractured abutment and a fractured screw were represented in figures 6 and 7 together with their intact originals. Presence of angulated abutments, cantilevering, non-passive fit of superstructure prosthesis, excessive tightening greater than the comments of the manufacturer, may cause such fractures [20]. However, crown/implant ratio and the number of implants supporting an FPD have not found as associated with increase in mechanical complications [9]. Compressive deformation of abutment occurs during the tightening of the both abutment screw and prosthetic cylinder screw has been demonstrated but the difference among the groups of abutments, $\mathrm{Pd}-\mathrm{Ag}$ and Co-Crprosthetic cylinders was not found significant [20]. In an acceptably passive fit, torque application compresses the counterparts to each other and some amount of deformation can normally be expected. But this deformation should be homogenous [20]. In a literature review study it has been advocated that, none of the mechanical risk factors had an impact on implant survival and success rates [9]. 
Association of the technical complications with bruxism was revealed with a retrospective investigation [10]. Out of 10 bruxers 6 had a technical complication whereas 13 out of 75 non-bruxers had such a complication. With this study, relation between the technical complications and extensions of the FPDs was also demonstrated. Thirteen out of 35 FPDs with extensions, had exhibited technical complications while 9 out of 81 FPDs without extensions showed similar problems [10].

Occlusal loads exceeding the inherent strength of the implant material may cause fracture of the implant body itself $[6,8]$. Implant body fracture was reported as one of the major causes of late implant failures and it was attributed to the biomechanical overload caused by parafunctional habits [21]. According to the results of an investigation reporting the treatment of thirty-nine patients having fractured implants; $90 \%$ of the fractures occurred in posterior region. $77 \%$ of the prostheses have been supported by one or two implants, which have been exposed to a combination of cantilever load magnification and bruxism or heavy occlusal loads. In conclusion it was noted that, bending overload risk is increased in prostheses supported by one or two implants and having cantilever extension [24]. An operative protocol consisting the steps of the flattening and smoothing the fracture surface, retapping the internal screw and installing a new and longer abutment, was described to manage the fractured fixture [21].

\section{Infectious Failures}

Lack of primary stability, surgical trauma due to the inappropriate surgical manipulation of the host tissues, infections and insufficient postoperative care, may obstacle the establishment of osseointegration [5,11]. However, properly osseointegrated implants too, may disintegrate due to the various reasons [5]. Occlusal overload and periimplantitis were reported as the most important factors associated with late failure [11].

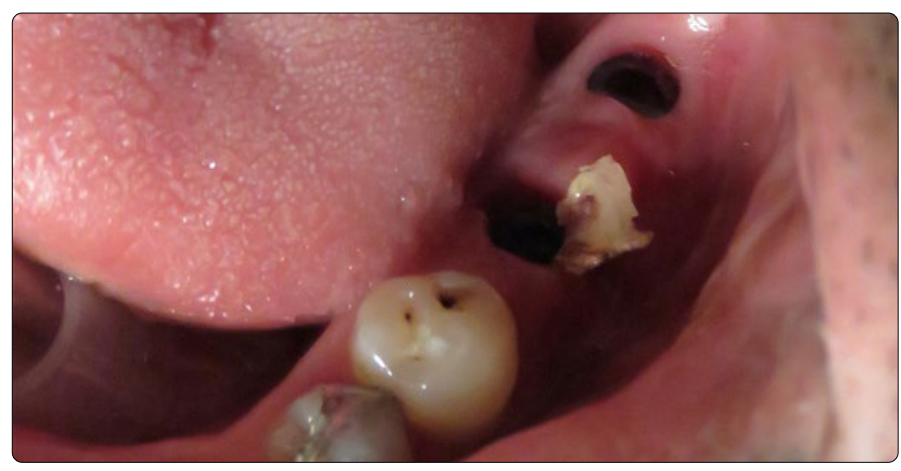

Figure 8. Cement remnants removed from the periphery of an implant exhibiting the soft tissue swelling and pain.

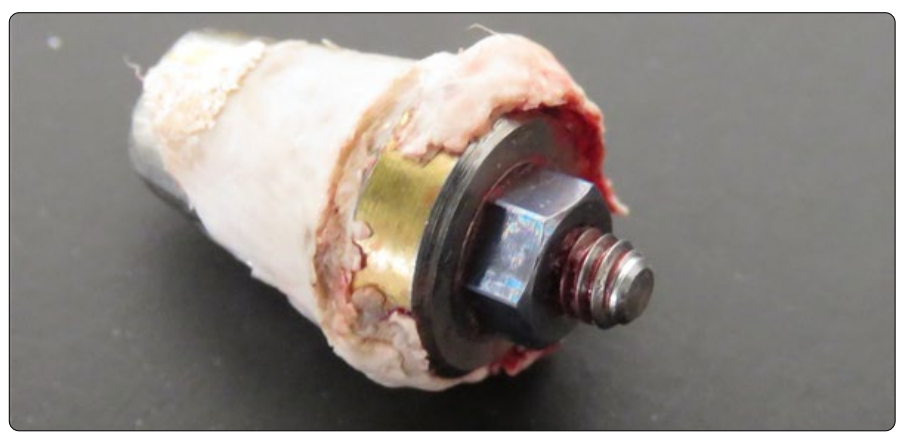

Figure 9. Excess cement remnants on the abutment of the case presented in fig. 8.

Infection of the surrounding tissues of an already osseointegrated implant is called as periimplantitis and known as one of the possible causes of implant failure with or without overload $[1,5,6,8]$. Periimplantitis as an inflammatory response is characterized with the loss of the bony support of implant. Diagnosis depends on the manifestations of infection. Signs were reported as the gingival inflammation, dehiscence, fistulas, hyperplastic soft tissues, suppuration, colour changes of the peri-implant gingiva and gradual loss of the host bone and may have many common features of the chronic adult periodontitis $[5,8]$. Inflammation arises from infragingival cement remnants; inappropriate preservation and injury of bone and soft tissues may occasionally lead periimplantitis [6]. Figure 8 represents the cement remnants removed from the periphery of an implant exhibiting the soft tissue swelling and pain. Excess cement remnants can also be seen on the abutment of the same case in figure 9 . It was recommended that it should be paid attention to the early signs of infection because they may be an indication of a much more critical results [11]. Crestal bone loss has been known as one of the initial detectable signs of implant overload [25]. Suboptimal implant design and improper prosthetic reconstruction were mentioned among the risk factors responsible for periimplantitis and overload followed by implant loss [11].

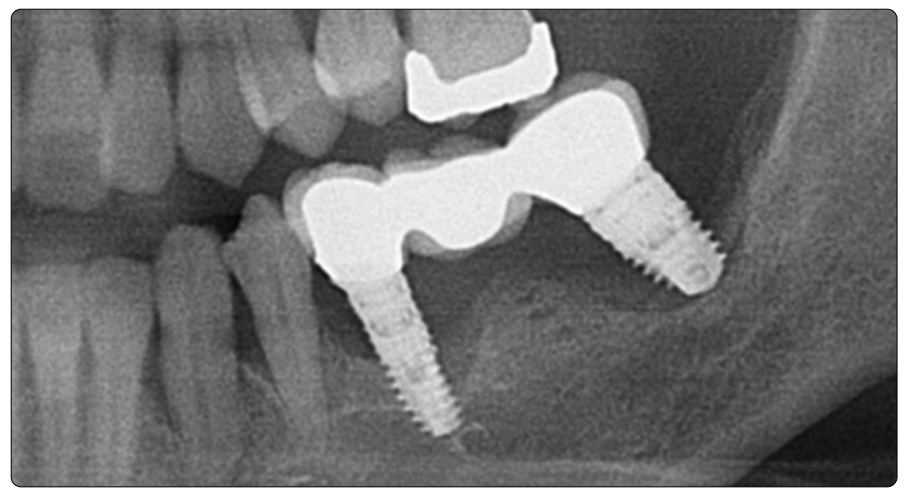

Figure 10. Radiographic representation of an implant failed due to the periimplantitis and/or overload.

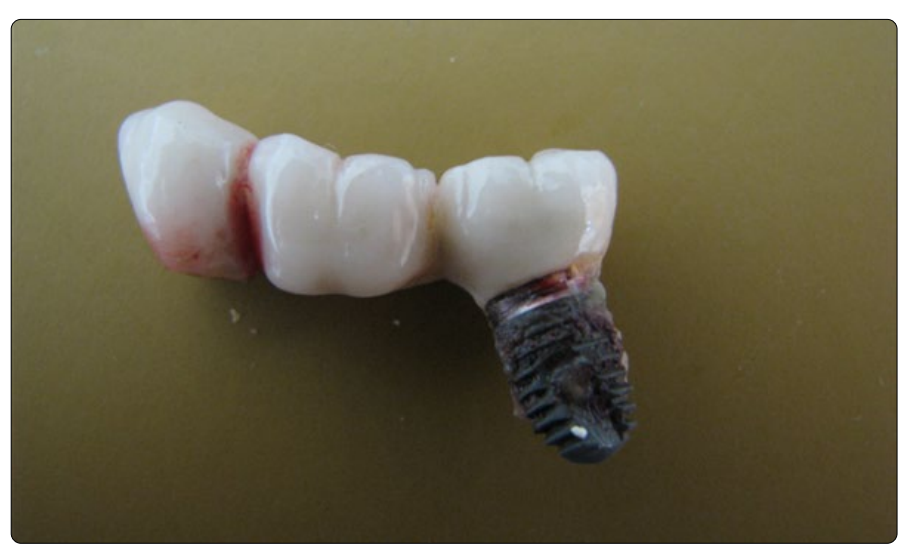

Figure 11. Failed implant presented in fig. 10 explanted with FPD superstructure.

The lack of osseointegration may easily be distinguished clinically by implant mobility and can be seen radiological. In this situation, the implant can be considered as failed. Progressive marginal bone loss without marked mobility is referring to a failing implant $[5,25]$. Figure 10 shows the 
radiographic representation of an implant failed due to the periimplantitis. Figure 11 represents the same implant with the incorporated superstructure FPD after explantation.

Histo-pathological alterations in the bone surrounding overloaded implants were inspected with animal studies [18,19].

Preoperative planning of the number, location, size and angle of the implants according to the quality and quantity of the host site, will dominate the success of the forthcoming prosthetic reconstruction [25]. Survival rates of the maxillary and mandibular implants were found different. Greater implant loss rates were reported in maxilla than mandible [8]. Relation between the implant loss and the quality of the host bone has also been demonstrated. The rate of failing implants supporting the maxillary overdentures, the rate of failing implants in type IV bone and the rate of failing implants in irradiated maxillae; were reported as 25\%, $16 \%$ and $25 \%$ respectively [7]. A statistically increase in implant loss with short implants and poor bone quality were reported [8].

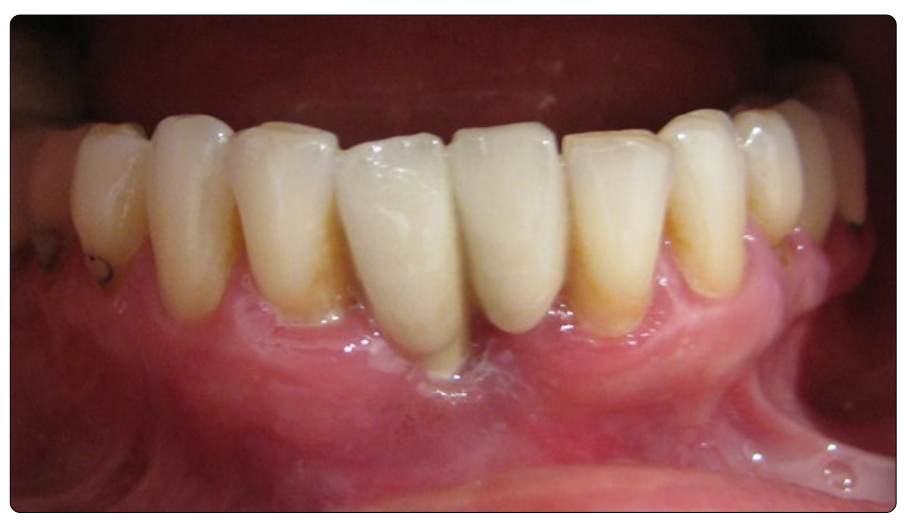

Figure 12. Two-unit cantilever FPD on a single implant failed due to periimplantitis and/or overload.

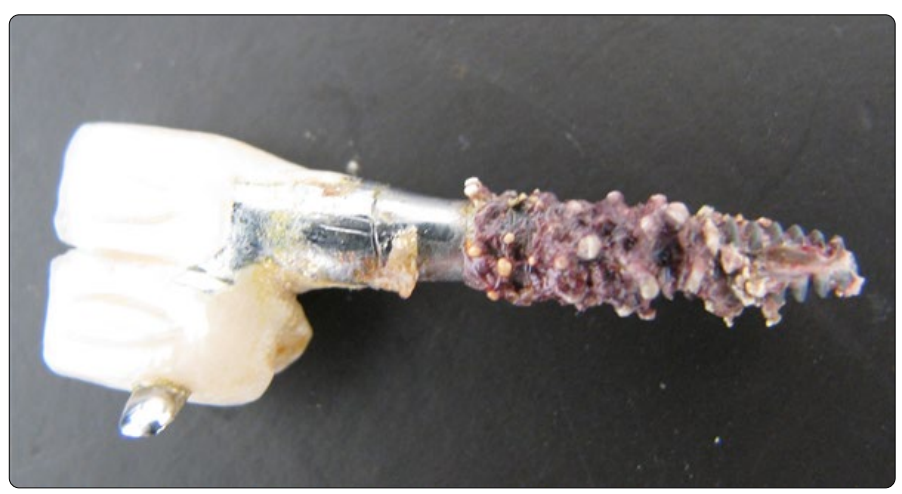

Figure 13. Failed implant presented in fig. 12 explanted with FPD superstructure.

Type and design of the prosthodontic superstructure may provoke implant loss according to the reviewed literature [8, 10,25]. Greater implant loss was reported with overdentures than with other types of prostheses. Pre-prosthetic and postprosthetic implant loss rates were found as in relation with the type of the prosthesis [8]. With full-arch reconstructions either fixed or removable, greater loss in the maxilla than mandible has been reported, whereas less arch difference was noted with fixed partial dentures [8]. Cantilevering is one of the risk factors affecting the survival of the implants by creating harmful occlusal loads [24]. Figure 12 shows the two-unit cantilever FPD on a single implant failed due to periimplantitis.
Figure 13 represents the same implant with the incorporated superstructure FPD after explantation. Excessive parafunctional forces were found responsible to increase in the rate of structural failures as well as implant loss [5,10,25]. But, impaired general health status was not significantly associated with more biological failures [10].

\section{Discussion}

Overloading of the implants, infection of the periimplant tissues or the combination of the both is known as the possible causes of implant failure. In some animal studies, different histological features were reported around the disintegration areas of overloaded and infection-induced implants [18]. Overload and infection-induced disintegrations might have peculiar pathological mechanisms according to this result. Nevertheless, responses of the peri-implant bone tissue to the excessive occlusal forces may exhibit conflicting results [19]. Applied load exceeding the biologically acceptable limit, may cause either marginal bone loss or total loss of osseointegration of an already osseointegrated dental implant. But this biological limit is unknown and differs individually. Furthermore, higher remodeling activity of the peri-implant bone was reported around implants subjected to high loading forces [19]. Considering this, it is not easy to find which one is the main etiological factor in a particular case [1].

Overload, either with or without periimplantitis, can easily be diagnosed clinically and radiographically [6]. Classical early signs of the chronic adult periodontitis in the peri-implant area $[5,6,8]$, the radiologic capturing of crestal bone loss $[11,25]$ and most of the structural failures related with the loosening or fracture of various components [7,8,20,22], were reported astheinitial detectable manifestations of implant overload.

Large number of factors has been mentioned in reviewed literature in association with implant overload. Improper type of prosthetic superstructure for clinical condition and suboptimal prosthetic design; insufficient number, unsuitable size, location and angle of implants to support the restoration; insufficiency of supporting bone $[18,19,25]$, lack of posterior support; splinting to a natural tooth andexcessively cantilevering; have been listed as the factors associated with the preoperative planning and design of the implant supported prostheses $[11,22,25]$. Some factors related with clinical and laboratory proficiency such as the non-passive fit of the prostheses [11], excessive tightening of the main screws [20], insufficient maintenance of the components $[9,25]$, has also been mentioned. Insufficient strength of prosthetic materials is expected to resist functional and parafunctional forces $[9,20$, $23,25]$. Excessive parafunctional forces have generally been susceptible from overload $[9,21,25]$. The negligence of fundamental prosthetic limitations for natural dentition has also been mentioned as associated with overload [25].

Distribution of the functional loads and minimizing the horizontal forces can diminish the implant overload. Balancing of the whole arch and the management of the masticatory forces were reported as more important than the type and 
design of the prosthetic superstructure [25]. Establishing synchronic, multi-point, balanced contacts in whole dental arch, avoiding the premature contacts during centric end eccentric relations and shortening or eliminating the cantilevers are known as the main precautions against implant overload. Both implant and prosthetic materials should be strong enough to resist intraoral forces, and the patient should also be instructed to maintain proper home care.

\section{Conclusion}

Under the lights of the reviewed literature and the sample cases, following conclusions were withdrawn:

Overload with or without infection, is the primary factor for most of the prosthetic and implant failures.

Generally, loosening of the screws and theradiographic evidence of marginal bone loss are better to be considered as the first detectable signs of implant overload, and warrant immediate action.

Advanced signs of overload are not far different from the classical manifestations of dental infection and inflammation and can be easily detected by peri-implant radiolucency.

Number, size, location and angle of the implants are better to be suitable to the superstructure prosthesis and also to hard and soft host tissues.

Quantity and quality of the host bone and attached gingiva are essential for the implant prognosis.

Centric and eccentric functional contacts should be balanced and occlusal interferences should be eliminated.

Patients with parafunctional habits should be managed meticulously.

\section{References}

1. Duyck J, Naert I. Failure of oral implants: aetiology, symptoms and influencing factors. Clin Oral Investig. 1998; 2: 102-14. doi: 10.1007/ s007840050054

2. Jemt T, Lekholm U, Adell R. Osseointegrated implants in the treatment of partially edentulous patients: a preliminary study on 876 consecutively placed fixtures. Int J Oral Maxillofac Implants.1989; 4: 211-7.

3. Jemt T. Failure of oral implants: aetiology, symptoms and influencing factors. Clin Oral Implants Res.1993; 4: 187-94.

4. Misch CE. Contemporary Implant Dentistry. Mosby Elsevier 3. Edition, St. Louis, 2008.

5. Sakka S, Coulthard P. Implant failure: etiology and complications. Med Oral Patol Oral Cir Bucal. 2011; 16: e42-4. doi: 10.4317/medoral.16.e42

6. Liaw K, Delfini RH, Abrahams JJ. Dental Implant Complications. Semin Ultrasound CT MR. 2015; 36: 427-33. doi: 10.1053/j.sult.2015.09.007

7. Goodacre CJ, Bernal G, Rungcharassaeng K, Kan JY. Clinical complications with implants and implant prostheses. J Prosthet Dent. 2003; 90: 121-32 doi: 10.1016/S0022-3913(03)00212-9

8. Goodacre CJ, Kan JY, Rungcharasaeng K. Clinical complications of osseointegrated implants. J Prosthet Dent. 1999; 81: 537-52. doi: 10.1016/S0022-3913(99)70208-8

9. Salvi GE, Brägger U. Mechanical and technical risks in implant therapy. Int J Oral Maxillofac Implants. 2009; 24: 69-85.

10. Brägger $U$, Aeschlimann $S$, Bürgin W, Hämmerle $\mathrm{CH}$, Lang NP. Biological and technical complications and failures with fixed partial dentures (FPD) on implants and teeth after four to five years of function. Clin Oral Implants Res. 2001;12:26-34.doi:10.1034/j.1600-0501.2001.012001026.x

11. Sakka S, Baroudi K, Nassani MZ. Factors associated with early and late failure of dental implants. J Investig Clin Dent. 2012; 3: 258-61. doi: 10.1111/j.2041-1626.2012.00162.x

12. Albrektsson $\mathrm{T}$, Branemark $\mathrm{Pl}$, Hansson $\mathrm{HA}$, Lindstrom J. Osseointegrated titanium implants. Requirements for ensuring a long-lasting, direct bonetoimplant anchorage in man. Acta Orthop Scand. 1981; 52: 155-70. doi: 10.3109/17453678108991776

13. Branemark PI. Osseointegration and its experimental background. J Prosthet Dent. 1983; 50: 399-410. doi: 10.1016/S0022-3913(83)80101-2

14. Jaffin RA, Berman CL. The excessive loss of Branemark fixtures in type IV bone: a 5-year analysis. J Periodontol. 1991; 62: 2-4. doi: 10.1902/ jop.1991.62.1.2

15. Schwarz MS. Mechanical complications of dental implants. Clin Oral ImplantsRes.2000;11(1):156-8.doi:10.1034/j.1600-0501.2000.011S1156.x

16. Skalak R. Biomechanical considerations in osseointegrated prostheses. J Prosthet Dent. 1983; 49: 843-8. doi: 10.1016/0022-3913(83)90361-X

17. Jemt T, Book K, Karlsson S. Occlusal force and mandibular movements in patients with removable overdentures and fixed prostheses supported by implants in the maxilla. Int J Oral Maxillofac Implants. 1993; 8: 301-8.

18. Pellegrini G, Canullo L, Dellavia C. Histological features of peri-implant bone subjected to overload. Ann Anat. 2012; 194: 529-32.

19. Chang $\mathrm{M}$, Chronopoulos $\mathrm{V}$, Mattheos $\mathrm{N}$. Impact of excessive occlusal load on successfully-osseointegrated dental implants: a literature review. J Investig Clin Dent. 2013; 4: 142-50. doi: 10.1111/jicd.12036

20. Neto RT, Moura MS, Souza EA, Rubo JH. Implant abutment deformation during prosthetic cylinder screw tightening: an in vitro study. Int $J$ Prosthodont. 2009; 22: 391-5.

21. Mendonça G, Mendonça DB, Fernandes-Neto AJ, Neves FD. Management of fractured dental implants: a case report. Implant Dent. 2009; 18: 10-6. doi: 10.1097/ID.0b013e318192

22. Jivraj SA, Chee WW. Use of a removable partial denture in the management of chronic screw loosening. J Prosthet Dent. 2005; 93: 13-6. doi: 10.1016/j.prosdent.2004.10.007

23. Jaarda MJ, Razzoog ME, Gratton DG. Ultimate tensile strength of five interchangeable prosthetic retaining screws. Implant Dent. 1996; 5: 16-9.

24. Rangert B, Krogh $\mathrm{PH}$, Langer B, Van Roekel N. Bending overload and implant fracture: a retrospective clinical analysis. Int J Oral Maxillofac Implants. 1995; 10: 326-34.

25. Swanberg DF, Henry MD. Avoiding implant overload. Implant Soc. 1995; 6 : $12-4$.

26. Preiskel HW. Precision Attachment in Dentistry. Henry Kimpton Publ. London, 1973. 